\title{
INFLUÊNCIA DA ORIENTAÇÃO HABITACIONAL SOBRE O NÚMERO DE ÁRVORES EXISTENTES NAS RUAS DE SERRA TALHADA - PE
}

\author{
Wellington Jorge Cavalcanti Lundgren ${ }^{1}$, Luzia Ferreria da Silva ${ }^{2}$, Mirella Almeida da Silva ${ }^{3}$, \\ Paula Emanuelle Rocha Pedrosa ${ }^{4}$
}

\section{RESUMO}

Foi realizado o censo da arborização na cidade de Serra Talhada, no qual foi criada a hipótese de que nas casas que recebem diretamente o sol à tarde os seus moradores tendem a plantar mais árvores do que nas casas que recebem o sol frontal pela manhã. Foram escolhidas 81 ruas, as ruas foram classificadas em dois tipos: Transversais (41 ruas) aquelas que possuíam inclinação maior que $45^{\circ}$ com o alinhamento Nascente-Poente do sol e Paralelas (40 ruas) aquelas que possuíam inclinação menor que $45^{\circ}$. As calçadas foram classificadas em dois tipos: Poentes, aquelas que recebiam o sol Poente em frente de suas casas e Nascentes, aquelas que recebiam o sol Nascente na frente de suas casas. Foram calculadas as distâncias médias entre as árvores (DM), também foi calculada a área média de cobertura vegetal das árvores (AC). O teste $\mathrm{F}$ ao nível de $5 \%$ foi usado para comparar as ruas (Transversais X Paralelas) e os lados (Poente X Nascente). Chegou-se a conclusão de que nas ruas transversais o lado poente possui mais árvores do que no lado nascente que inesperadamente as áreas de cobertura média das árvores no lado Nascente das ruas Transversais são maiores do que no lado poente e que para as ruas paralelas não havia diferença estatística nem entre o número de árvores e nem entre as áreas de cobertura.

Palavras-chave: Arborização Urbana; Radiação Solar; Semiárido Nordestino; Podas; Sombreamento.

\footnotetext{
Recebido em 20.12.2012 e aceito em 26.03.2014

1 Dr. em Ciências Florestais, Universidade Federal Rural de Pernambuco, UAST - wellingtolundgren@yahoo.com.br.

2 Dra. em Fitotécnia, Universidade Federal Rural de Pernambuco, UAST - Ifsilva68@hotmail.com.

3 Graduanda em Agronomia, Universidade Federal Rural de Pernambuco, UAST - mirellaalmeidas2@hotmail.com.

4 Graduanda em Agronomia, Universidade Federal Rural de Pernambuco, UAST - .p_pedrosa_@hotmail.com
} 


\title{
INFLUENCE OF ORIENTATION HOUSING ON THE NUMBER OF EXISTING TREES IN THE STREETS OF SERRA TALHADA CITY - PERNAMBUCO
}

\begin{abstract}
ABSTRAT
We conducted a census of afforestation in Serra Talhada city and noticed that the sidewalks who received the setting sun seemed to have more trees than the sidewalks who received the rising sun. The streets were classified into two types: a) those who had Transverse slope greater than $45^{\circ}$ to the east-west alignment of the sun. b) Parallel those who had less than $45^{\circ}$ slope. The sidewalks were classified into two types: i) sunsets, those who received the setting sun. ii) springs, those who received the rising sun. For comparison we used the average distances between trees (DM) and the average area of vegetation cover of trees (AC). The $\mathrm{F}$ test at the $5 \%$ level was used to verify statistical difference between the streets (Parallel X Cross) and sidewalks (East X West). Reached the conclusion that there is no difference between the cross streets and parallel streets and in the Transverse west side has a lower DM than on the East and unexpectedly that the AC in the East side is lower than the west side and for the parallel streets there was no statistical between the number of trees or between coverage areas difference.
\end{abstract}

Keywords: Urban Forestry; Solar Radiation; Semiarid Northeast; Pruning; Shading.

\section{INTRODUÇÃO}

Os benefícios de uma arborização planejada e bem acompanhada são bem conhecidos e já foram discutidos por vários pesquisadores. Shams et al. (2009) fizeram ampla discussão e levantamento bibliográfico sobre o conforto térmico em ambientes urbanos e sua relação com a arborização. Troy et al. (2012) realizaram pesquisa comprovando a correlação negativa entre a área de cobertura vegetal e a criminalidade em Baltimore nos EUA, cabe ressaltar que nessa pesquisa talvez as áreas da cidade com maior criminalidade sejam as áreas mais pobres e que essas áreas também tenham menor cobertura vegetal, e que as áreas mais ricas possuam maior cobertura vegetal e menor criminalidade e por conta da situação financeira entre os dois locais apareça a correlação negativa. 
O censo arbóreo de toda a cidade não é pratica comum em planejamento urbano é mais usual a realização de censos de ruas ou bairros, proporcionalmente poucos municípios brasileiros realizam o censo total da cidade, Alvarez (2004) afirma que o processo é caro, trabalhoso e demorado e sugere a utilização de amostragem para a tomada de decisões, $O$ autor efetuou amostragem em Piracicaba - SP e comparou com o censo obtendo resultados satisfatórios para a estimativa do número de árvores por rua e dimensões das copas. Sampaio e De Angelis (2006) realizaram o censo das árvores urbanas das vias públicas de Maringá-PR que é cidade referência em termos de arborização urbana no Brasil e possuía população de 320.000 habitantes na época do censo. O censo também foi realizado no município de Lavras da Mangabeira - CE por Calixto Júnior et al. (2009) onde foram contabilizadas 2.784 árvores nas ruas, nas avenidas, nas praças, nos terrenos públicos e privados a cidade possui uma população de 31.000 habitantes, portanto pode ser considerada uma cidade pequena, em que o censo não se torna tão trabalhoso.

Quando tratamos de cidades brasileiras localizadas no semiárido nordestino, a arborização urbana é assunto alheio a administração pública para a grande maioria dos municípios. Milano e Dalcin (2000) realizaram pesquisa envolvendo pequenas e medias cidades do semiárido nordestino e verificaram o despreparo da administração pública sobre o assunto. As árvores quando são plantadas não seguem nenhum critério a não ser o desejo e a vontade daquele que a decidiu plantar. Muitas vezes árvores não adequadas são colocadas em locais onde simplesmente causarão futuros transtornos, exigindo futuras intervenções.

As cidades localizadas no semiárido nordestino recebem intensa radiação solar durante todo o ano, o sol é um limitador de locomoção no sentido de que as pessoas preferem ficar em ambientes cobertos nos horários de maior intensidade solar que vai das 11:00 horas até as 15:00 horas, não foi encontrado estudos sobre a observação aqui exposta sobre a locomoção das pessoas, porém Frota e Schiffer (2006) afirmam que a temperatura ambiente é fator de conforto para o ser humano e que a atividade física tende a diminuir drasticamente quanto à temperatura ambiente é aumentada provocando desconforto.

Devido à intensa irradiação solar existente no semiárido nordestino era de se esperar que essas cidades fossem bem arborizadas e possuíssem muitas árvores frondosas que fornecessem sombra e melhorassem o conforto térmico.

Porém o que acontece na cidade de Serra Talhada - PE onde foi efetuada essa pesquisa é justamente o contrário, as árvores são poucas, e em quase sua totalidade podadas de forma a reduzir acentuadamente sua área de cobertura, o hábito da poda é 
extremamente arraigado entre a população, o que prevalece é o conceito de que árvore, só é bonita e bem cuidada se for podada regularmente para que adquira forma geométrica considerada bela, cilíndrica, cúbica ou cônica, não há preocupação com o sombreamento, além disso, segundo Nascimento et al. (2009) muitos moradores consideram que as árvores são elementos urbanos que provocam mais malefícios do que benefícios, pois elas entram em contato com a fiação elétrica, sujam o chão com suas folhas e quebram as calçadas.

A hipótese desse trabalho é que nas casas em que o solo é um grande incômodo por incidir diretamente na frente da residência na hora mais quente do dia que é à tarde, os moradores costumam plantar árvores como forma de barreira contra essa insolação, e que nas casas onde o sol não incide diretamente, a maioria dos moradores evitam o plantio.

\section{MATERIAIS E MÉTODOS}

A pesquisa foi realizada na cidade de Serra Talhada localizada na latitude $07^{\circ} 59^{\prime} 31^{\prime \prime}$ Sul e longitude $38^{\circ} 17^{\prime} 54^{\prime \prime}$ Oeste, na Mesorregião do Sertão pernambucano na Microrregião do Pajeú, a uma altitude de 429 metros, a cidade possui uma população estimada em torno de 80.000 habitantes (IBGE, 2010).

Figura 1. Localização da cidade de Serra Talhada - PE

Figure 1. Location of the Serra Talhada city - PE

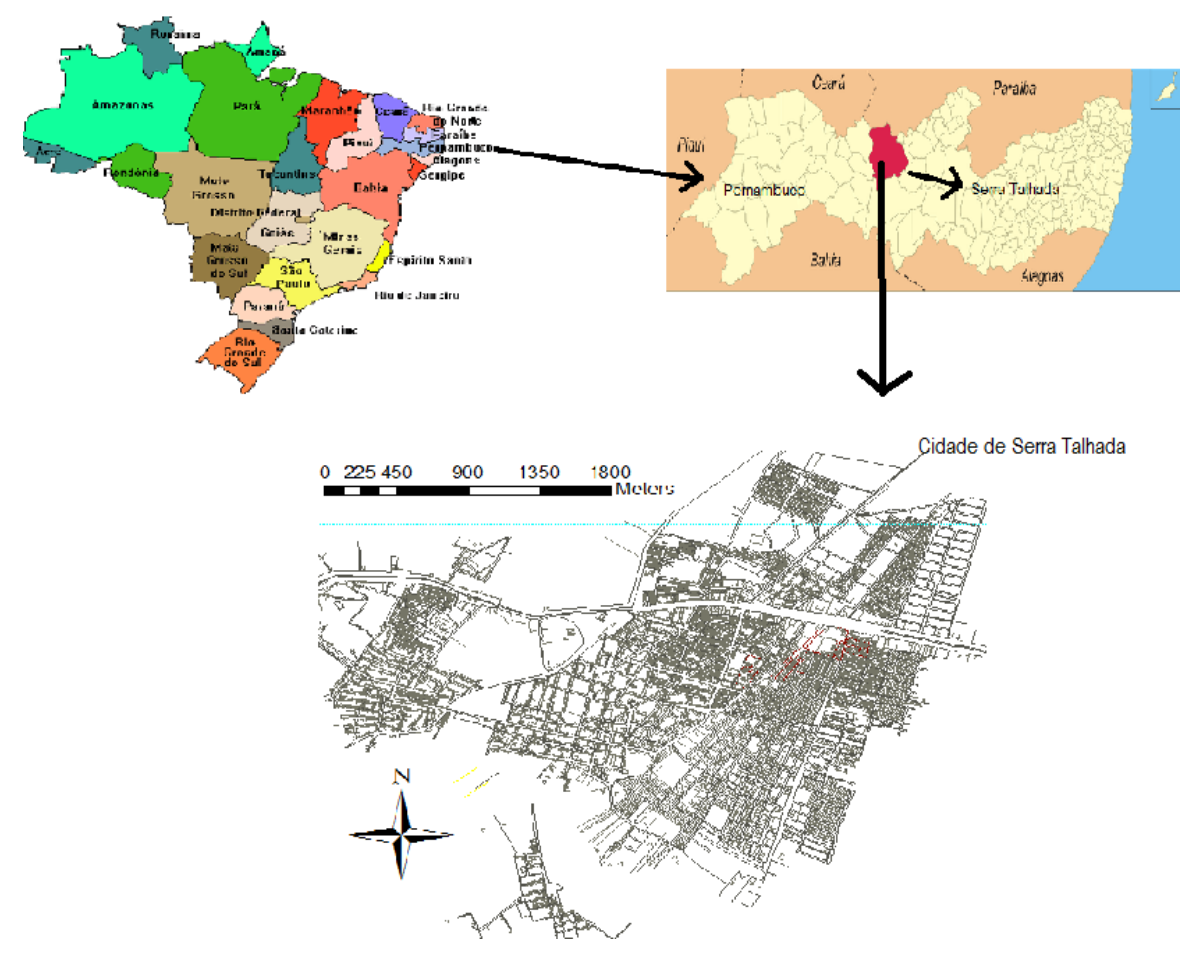


O censo das árvores localizadas nas calçadas da cidade de Serra Talhada foi realizado entre os meses de Junho de 2011 e setembro de 2012, duas equipes compostas de três estagiários percorreram todas as ruas anotando em planilha, o número da árvore, o número da casa ou construção em geral, a localização geográfica pelo GPS, o nome da rua, o construção em geral, a localização geográfica pelo GPS, o nome da rua, o bairro, a altura estimada, o diâmetro da copa, a distância entre as árvores de uma mesma calçada e o nome comum.

Os dados do GPS foram passados para o software Tracmaker e desses repassados para o software Excel onde também foram colocadas todas as informações da planilha de coleta e posteriormente exportados para o software ArcGis. O software ArcGis possuía o mapa georreferenciado da área urbana de Serra Talhada e com ele foi possível construir o mapa de arborização das calçadas da zona urbana do município. Em que a área das copas foi colocada na mesma escala do mapa. O georreferenciamento é prática que se tornou comum nos últimos anos para administração e manejo de arborização urbana. Rocha et al. (2012) utilizaram SIG (Sistema de Informações Geográficas) para realizar o censo arbóreo do bairro dos Aflitos na cidade de Recife em que o interesse foi inventariar o número de árvores e identificar as espécies existentes e verificar se as árvores estavam em conflito com as estruturas urbanas, eles chegaram à conclusão de que o SIG (Sistema de Informação Geográfica) foi eficiente para a interpretação dos resultados.

Nessa pesquisa foram escolhidas oitenta e uma das duzentos e quarenta e uma ruas da cidade e separadas em duas categorias, as primeiras denominadas de "Transversais" com inclinação de até $45^{\circ}$ com a linha Nascente-Poente (41 ruas) e as restantes denominadas de "Paralelas" com inclinação menor que $45^{\circ}$. Klüppel (2000) realizou pesquisa analítica sobre a urbanização de Salvador - BA, o qual é destacado o fator posição da rua em relação ao nascer do sol, como aspecto importante para o conforto urbano.

Os lados de cada rua foram denominados de "Nascente" quando o sol incide sobre a frente da casa ao nascer e o lado "Poente" quando o sol incide sobre a frente da casa ao se pôr, as figuras 2 e 3 apresentam os esquemas de separação entre as ruas e entre as calçadas.

A quantidade de árvores para cada lado da rua foi contada e a área de cobertura $\left(\mathrm{m}^{2}\right)$ para cada árvore foi anotada, também foi medido o comprimento da rua $(\mathrm{m})$ usando o software ArcGis 9.3.

A figura 4 apresenta uma parte da cidade do bairro São Cristóvão em Serra Talhada e demonstra as árvores distribuídas geograficamente em relação aos lados das ruas. 
Acompanhando-se visualmente algumas das ruas apresentadas na figura, principalmente aquelas denominadas de transversais é fácil perceber que o lado Poente geralmente possui mais árvores que o lado Nascente.

Figura 2. Parte do mapa arbóreo do bairro São Cristóvão em Serra Talhada, os pontos representam as árvores em escala em relação à área de cobertura vegetal

Figure 2. Part of the map of trees of the neighborhood São Cristóvão in Sierra Talhada, the points represent the trees in scale compared to area vegetation

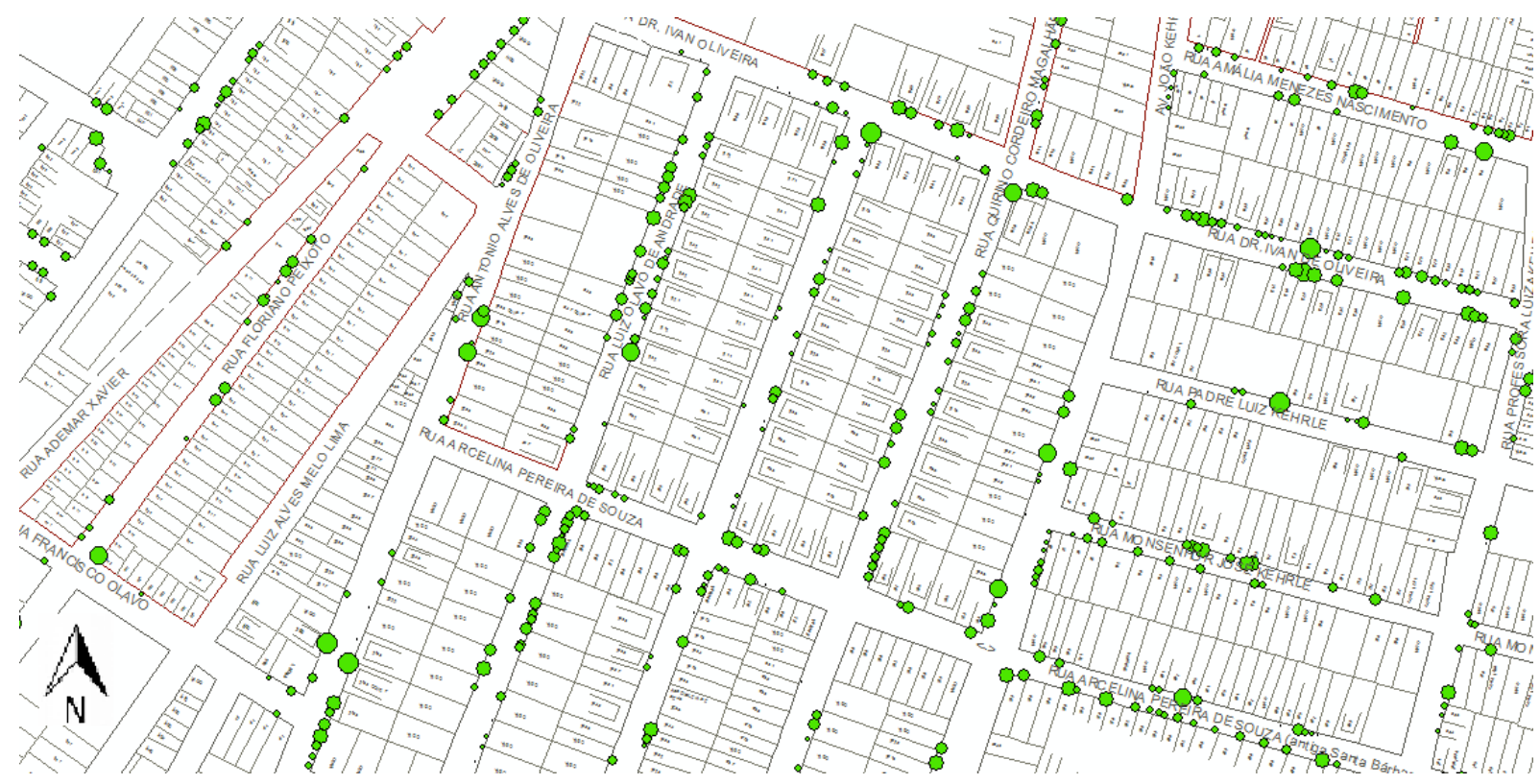

Para comparação entre os lados ponte e Nascente foram utilizados os seguintes indicadores: distância média entre as árvores (DM), nesse indicador quanto menor o valor de DM mais árvores existem na calçada ou maior o adensamento de árvores. Também foi usada como indicador a área de cobertura média em $\mathrm{m}^{2}$ por árvore $(\mathrm{AC})$, sendo possível verificar com essa medida se as árvores das calçadas ou das ruas são em média maiores do que as do outro lado.

Para o cálculo da DM foi utilizada a fórmula [1] esse indicador fornece a distância média em metros existente entre as árvores das ruas, pois as ruas transversais e Paralelas não possuem obrigatoriamente os mesmos comprimentos, se usássemos apenas o número de árvores esse indicador ficaria comprometido. Portanto quanto maior for o DM menor será o número de árvores existentes nas calçadas.

Para o outro indicador, a área de cobertura em metros quadrados por árvore (AC), foi utilizada a fórmula [2], quanto maior o valor do índice maior será a área de cobertura média por árvore. 


$$
D M=\frac{T C}{N C}
$$

Em que:

DM = distância média entre as árvores da mesma calçada.

$\mathrm{TC}=$ comprimento total das calçadas em metros .

$\mathrm{NC}=$ número total de árvores da rua.

$$
A C=\frac{\sum_{i=1}^{N C} C C_{i}}{N C}, \quad i=1,2,3, \ldots, N C
$$

Em que:

$\mathrm{AC}=$ Área média de cobertura por árvore.

$\mathrm{CC}=$ área de cobertura de cada árvore.

$\mathrm{NC}=$ número total de árvores da rua.

A análise de variância utilizando o teste $F$ ao nível de $5 \%$ verificou se existe diferença significativa entre os lados da rua e entre os dois tipos de ruas.

Gráficos de coluna foram construídos para apresentar as diferenças encontradas entre os lados Poentes e Nascentes e os dois tipos de ruas Transversais e Paralelas, os indicadores foram comparados por análise de variância e o p-valor utilizado como parâmetros estatístico.

\section{RESULTADOS E DISCUSÃo}

\section{Diferença entre os dois tipos de ruas: Transversais e Paralelas}

Foi verificado se existe diferença entre as ruas transversais e Paralelas como um todo, para comparar se a população se comporta diferentemente em relação ao plantio de árvores em suas calçadas dependendo da inclinação de incidência do sol na parte frontal de suas casas foram construídos dois gráficos de colunas apresentados na Figura 5. Os benefícios que as árvores fornecem para a amenização da temperatura são bem conhecidos e estudados por vários cientistas (SHAMS et al., 2009; MASCARO, 2006; SIMPSON, 2002), pesquisou sobre a influência da altura, copa e posição das árvores em relação à edificação e a diminuição nos gastos com energia elétrica na cidade de Sacramento nos EUA e chegou 
à conclusão de que se esses aspectos forem considerados a economia de energia é significativa.

A Figura 3 apresenta os gráficos (A) para a distância média entre as árvores em metros que dá uma ideia da quantidade de árvores existente nas calçadas, ou seja, quanto maior o valor de m mais espaçadas as árvores umas das outras, a informação é importante para dimensionar o quanto à população usa de árvores para se proteger dos raios solares em frente a suas casas e o gráfico (B) para a cobertura vegetal em metros quadrados por árvore, quanto maior a área, maiores serão em média as árvores usadas nas proteções contra os raios solares em frente a suas casas.

Figura 3. Gráficos de colunas para a distância entre as árvores $(A)$ e da cobertura vegetal (B) para as ruas transversais e Paralelas

Figure 3. Column Charts for the distance between the trees $(A)$ and vegetation cover $(B)$ to cross streets and parallel

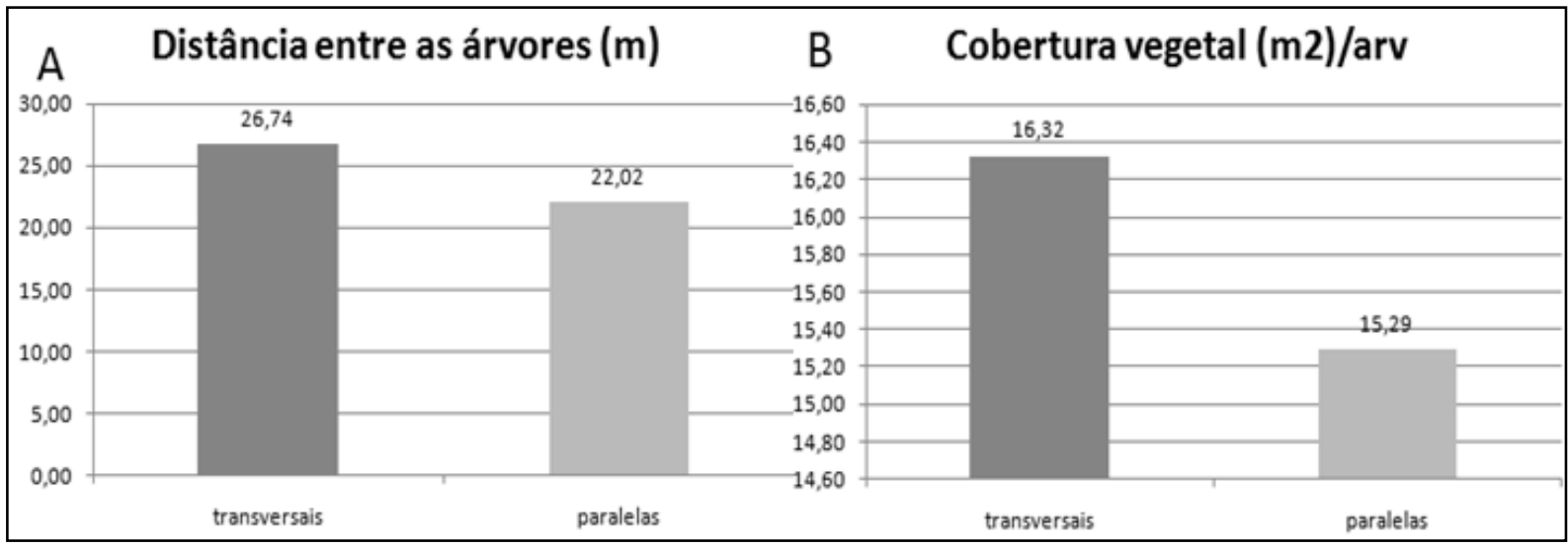

As ruas transversais apresentaram uma distância média de 26,74 metros entre as árvores, considerando que o valor médio para do diâmetro das árvores de Serra Talhada é aproximadamente 3,63 metros, foi percebido como as ruas transversais são pouco arborizadas e as árvores muito distanciadas umas das outras, para cada 3,63 metros lineares de sombra temos quase 23 metros lineares de calçada sob sol escaldante.

Quando comparamos os valores anteriores com os das ruas Paralelas a situação não parece ser muito diferente, porém há um acréscimo no adensamento, pois a distância entre as árvores diminuiu para 22,02 metros. Porém essa diferença não é significativa ao nível de $5 \%$ pelo teste $F$, o $p$-valor foi de 0,12 então podemos afirmar que a população não percebe a diferença entre as ruas transversais e as ruas Paralelas quando o fator de comparação é o número de árvores plantadas por metro de calçada dessas ruas.

A explicação para a não existência de diferença pode ser o grande adensamento das árvores no lado Poente das ruas transversais, geralmente maior que o dobro do 
adensamento do lado Nascente das ruas transversais, e nas ruas Paralelas, o adensamento ser igual nos dois lados da rua, compensado a diferença e igualando o adensamento das duas ruas como um todo.

Para a comparação entre os dois tipos de ruas foi considerado o comprimento total das calçadas incluindo as calçadas do lado Poente e as do lado Nascente, o menor número de árvores por metro linear nas ruas transversais se deve ao fato que nessas ruas a população que reside do lado Nascente não costuma em sua maioria plantar árvores nas calçadas, já nas ruas paralelas encontramos árvores nos dois lados das calçadas na mesma proporção, o que aumenta a densidade linear.

Será que as árvores possuem tamanhos de copas diferenciados dependendo do tipo de rua? Observando o gráfico (B) da figura 3, vemos que em média as árvores das ruas transversais possuem áreas de copas maiores com 16,32 metros quadrados por árvore, porém as árvores das ruas Paralelas não são tão diferentes nesse aspecto, pois cada uma delas cobre 15,29 metros quadrados com sombra. O teste $F$ nos dá um p-valor de 0,22 mostrando que não existe diferença significativa ao nível de 5\%, as árvores não possuem tamanhos diferenciados quando comparamos os tipos de ruas, esse resultado era esperado, pois se percebe andando nas ruas da cidade que o costume é manter as árvores podadas aproximadamente todas do mesmo tamanho, não diferenciando muito se é Ficus, Acácia ou Nin, Lundgren et al. (2013) verificaram que essas três espécies compõem 93\% das árvores existentes na cidade.

\section{Diferença entre os lados Poentes das ruas transversais e Paralelas}

Foi verificado se no lado Poente existe diferença entre as ruas transversais e Paralelas. Na parte da manhã as ruas transversais não recebem os raios de sol em frente das casas que se localizam nas calçadas Poentes e a tarde esses raios incidem na frente das casas com sua maior intensidade.

Quando se trata das casas das ruas Paralelas o comportamento é similar, com a pequena diferença de que a tarde a incidência dos raios solares nas calçadas poentes não é tão direto, o que ameniza o pouco a temperatura dessas casas.

A Figura 4 mostra os gráficos de coluna para a distância média entre as árvores em metros e a cobertura em metro quadrado por árvore para os lados Poentes das ruas transversais e Paralelas. 
Figura 4. Gráficos de coluna da distância entre as árvores e da cobertura vegetal para o lado Poente das ruas transversais e paralelas

Figure 4. Charts column on the distance between the trees and vegetation to the west cross streets and parallel

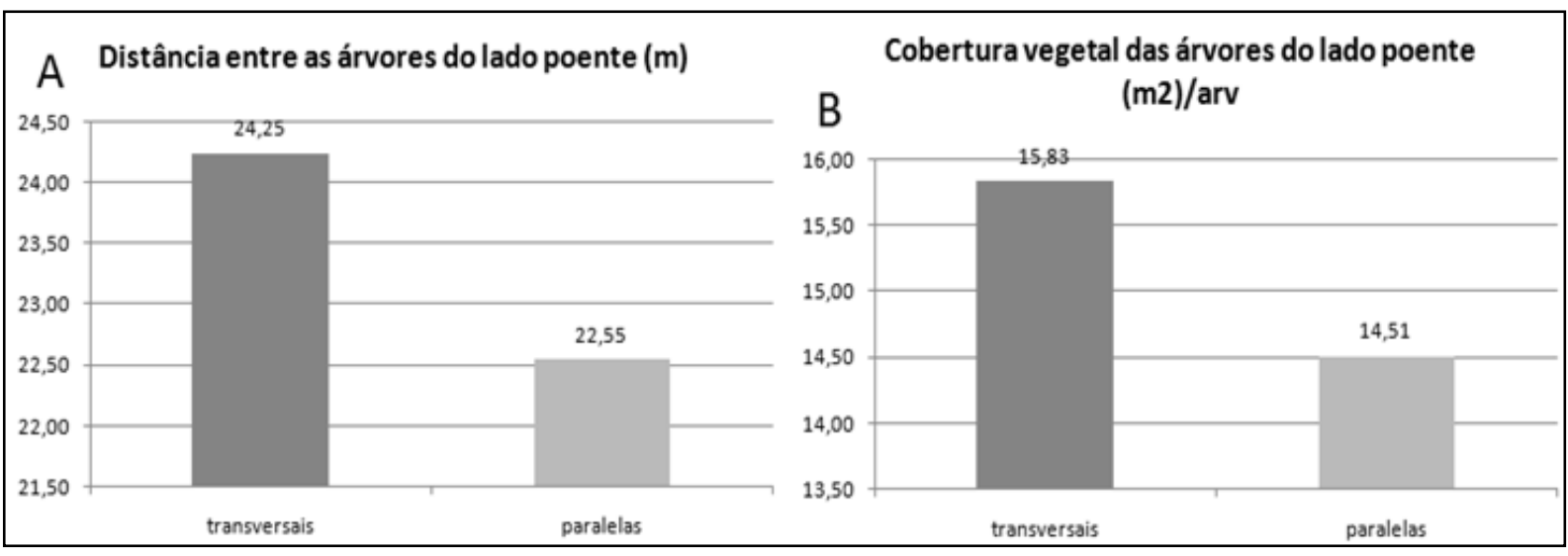

Como pode ser visto no gráfico $(\mathrm{A})$ da Figura 4, para as ruas transversais o adensamento das árvores nas calçadas Poentes é menor, existem em média menos árvores nas calçadas Poentes das ruas transversais do que nas calçadas Poentes das ruas Paralelas, ou seja, nas ruas transversais as calçadas do lado Poente estão mais distanciadas uma das outras do que nas calçadas do lado Poente das ruas Paralelas, porém essa diferença não é estatisticamente comprovada pelo teste $F$ ao nível de $5 \%$, que forneceu o p-valor de 0,60.

A diferença a maior para o lado Poente das transversais versus as Paralelas não era esperada, pois o sol incomoda da mesma maneira as residências que estão desse lado da calçada, o que muda é a intensidade um pouco menor para as ruas Paralelas. Sendo assim o esperado era que nas Paralelas o espaçamento entre as árvores fosse um pouco maior.

O gráfico (B) da figura 05 apresenta a área de cobertura média para os lados Poentes dos dois tipos de ruas, as ruas transversais apresentaram árvores com maiores copas do que as árvores das ruas Paralelas, porém essa diferença não é significativa pelo teste $\mathrm{F}$ ao nível de $5 \%$ que forneceu um $\mathrm{p}$-valor de 0,45 . Esse resultado reforça a impressão intuitiva de que as árvores da cidade possuem em sua grande maioria copas com tamanhos semelhantes, esse fato esta ligado diretamente às podas constantes.

\section{Diferença entre os lados Nascentes das ruas transversais e paralelas}

Os lados Nascentes das ruas transversais recebem o sol da manhã na frente das casas, que é normalmente mais ameno do que o sol da tarde, para as ruas Paralelas, 
dependendo da inclinação que ela possua em relação ao Nascente-Poente, o sol da tarde pode vir a incomodar com maior ou menor intensidade. A figura 5 no gráfico $(A)$ apresenta 0 gráfico de coluna em relação ao espaçamento entre as árvores para o lado Nascente das ruas transversais e Paralelas.

Figura 5. Gráficos de coluna da distância entre as árvores e da cobertura vegetal para o lado Nascente das ruas transversais e Paralelas

Figure 5. Charts column on the distance between the trees and vegetation for the eastern side of the cross streets and parallel

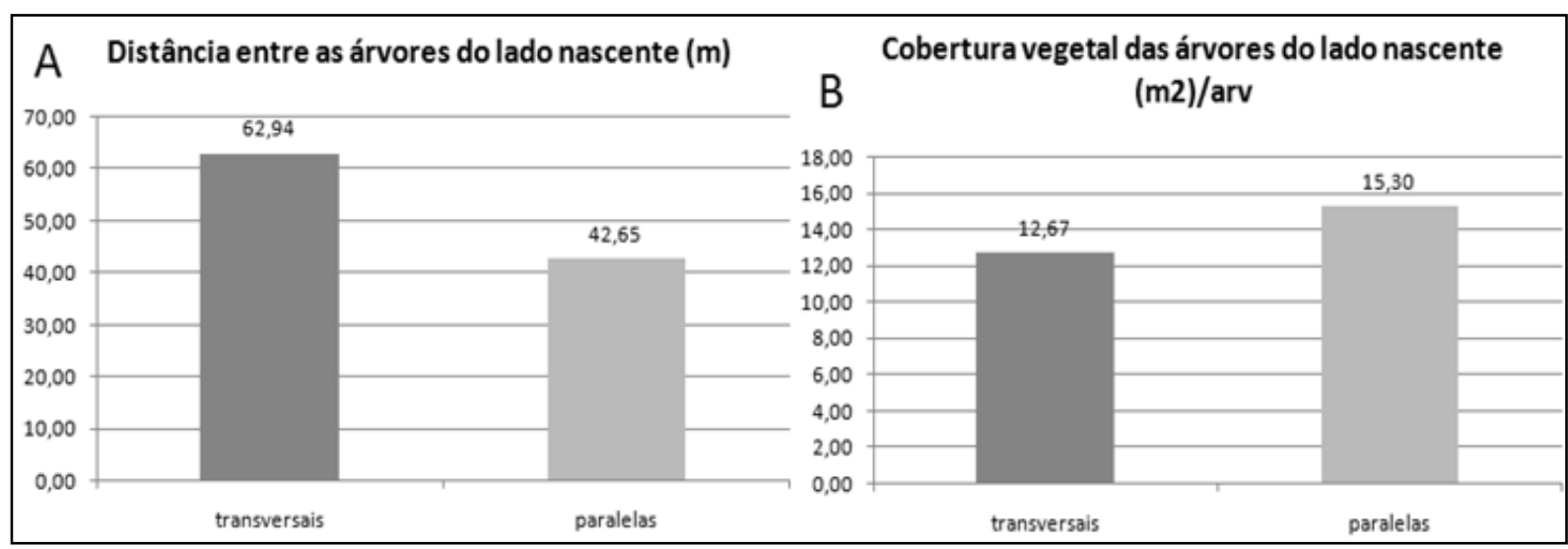

Como esperado, as árvores dos lados Nascentes são mais espaçadas nas ruas transversais do que nas ruas Paralelas, como foi comentado anteriormente, os lados Nascentes dessas ruas não recebem diretamente os raios solares na parte mais quente do dia que é à tarde, "necessitando, portanto de menos árvores".

$\mathrm{O}$ teste $\mathrm{F}$ forneceu um $\mathrm{p}$-valor de 0,0679 o que decreta que não existe diferença estatisticamente comprovada na densidade de árvores plantadas nas calçadas do lado Nascente para as ruas transversais e Paralelas. É importante ressaltar que o $p$-valor foi bem perto de 0,05 (valor limite para considerar diferença), ou seja, se aumentássemos nossa incerteza sobre a afirmação de igualdade para 7\%, consideraríamos que as duas populações seriam diferentes.

Para as ruas Paralelas, o sol da tarde ainda é um forte incômodo para os lados Nascentes, isso dependendo da inclinação dessas ruas em relação ao eixo NascentePoente, daí o maior adensamento para os lados Nascentes das ruas Paralelas.

O gráfico $(\mathrm{B})$ da figura 06 apresenta a área de cobertura por árvore para os lados Nascentes das ruas transversais e Paralelas. As duas médias são bem próximas, o teste $\mathrm{F}$ forneceu um p-valor de 0,1431 descartando a existência de diferença entre as duas populações. 
A observação casada dos dois gráficos: distância entre as árvores e cobertura vegetal para o lado Nascente mostra que para as ruas transversais que não recebem o sol da tarde diretamente na frente das casas, tanto o adensamento das árvores nas calçadas é menor, como os tamanhos das copas também são menores do que nas ruas Paralelas, nessas para o lado Nascente o adensamento é e o tamanho da copa também são maiores.

O que é um indicativo de que as ruas Paralelas recebem maior insolação do que as ruas transversais e de que a população percebe esse fato e procura se proteger da situação.

\section{Diferença entre os lados Nascente e Poente para as ruas transversais}

Os gráficos $\mathrm{A}$ e $\mathrm{B}$ da figura 8 mostram a diferença entre o espaçamento médio entre as árvores e a área média de cobertura por árvore em metros quadrados respectivamente para os lados Poentes e Nascentes das ruas transversais, como os lados de uma rua possuem o mesmo comprimento esses índices são bons indicadores de diferença entre os lados.

Figura 6. Gráficos de coluna da distância entre as árvores e da cobertura vegetal para os lados Poentes e Nascentes das ruas transversais

Figure 6. Charts column on the distance between the trees and vegetation to the sides and springs sunsets cross streets

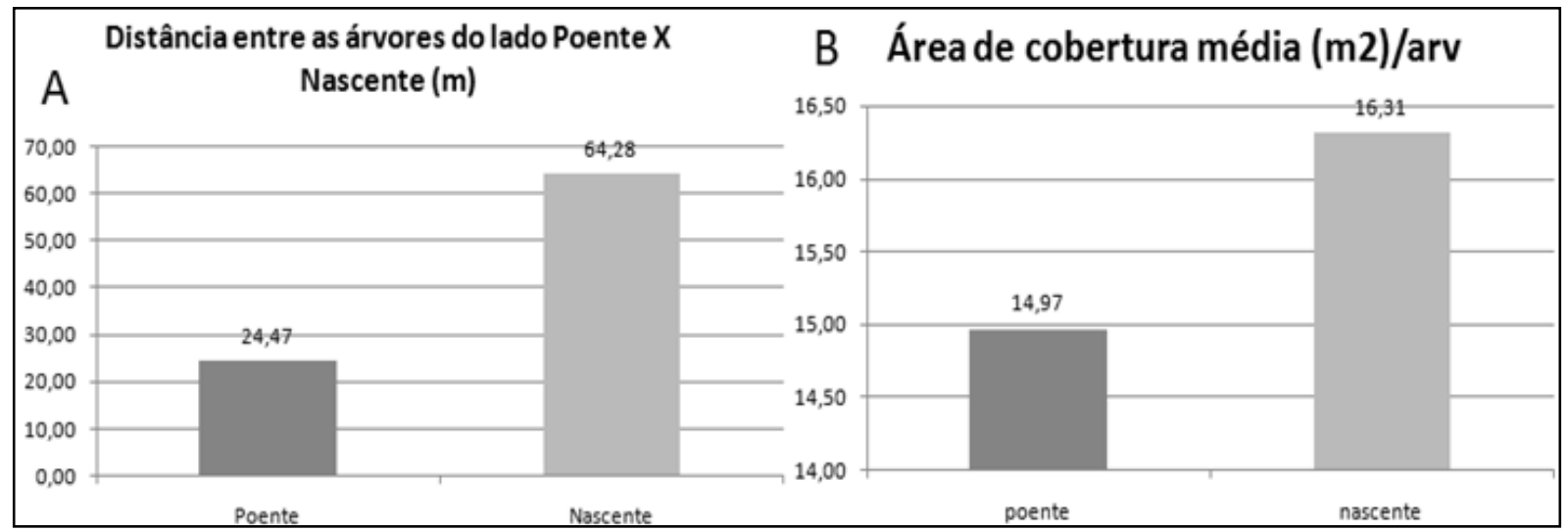

A densidade de árvores nos lados Poentes é duas vezes superior às árvores do lado Nascente, esse resultado já era esperado, pois visualmente esse fato foi percebido durante coleta de dados do censo e deu origem a atual pesquisa, o teste $F$ forneceu o $p$-valor $=$ 0,0001 indicando uma diferença estatisticamente comprovada ao nível de 5\%.

Esse resultado pode ser explicado pela alta temperatura que recebem as casas voltadas para o Poente, pois recebem os raios de sol diretamente na frente da casa, uma 
forma natural de amenizar esse desconforto é a construção de barreiras naturais tais como árvores. Mascaró et al. (2008) comentam em seu trabalho a importância das árvores para as fachadas que recebem a luz solar diretamente do Poente e do Nascente.

Para as casas voltadas para o Nascente, o problema da incidência direta da luz solar é amenizado, pois pela manhã a irradiação solar não é tão intensa, e o incômodo do calor não é tão acentuado. No período da tarde, quando a irradiação é mais intensa, essas casas não mais recebem a irradiação solar diretamente em suas frentes, não necessitando tanto de árvores em suas calçadas.

Nascimento et al. (2009) realizaram pesquisa domiciliar na cidade de Serra Talhada e verificaram que $37 \%$ dos moradores veem as árvores como um incômodo por sujar com folhas ou quebrar as calçadas, outra grande preocupação da população é com a fiação elétrica, talvez venha dessas observações estudadas por Nascimento, a lógica dos moradores das calçadas voltadas para o Nascente, "se eu não tenho sol incomodando, não preciso de árvore, é um incomodo a menos que vou ter".

Quando comparamos a área de cobertura média de cada árvore percebemos que a situação se inverte e inesperadamente as árvores dos lados Poentes que possuem em média $14,97 \mathrm{~m}^{2}$ de cobertura, parecem ser menores em área de cobertura do que as árvores do lado Nascente que possuem em média $16,31 \mathrm{~m}^{2}$, essa diferença é confirmada no teste estatístico $\mathrm{F}$ ao nível de $5 \%$, que fornece um $\mathrm{p}$-valor $=0,03$. Uma possível explicação para essa diferença seria que as árvores do lado Nascente, por serem em menor número, portanto, mais espaçadas umas das outras, faça com que os moradores deixem suas copas um pouco maiores que as das árvores do lado Poente.

\section{Diferença entre os lados Nascente e Poente para as ruas Paralelas}

A figura 7 mostra os gráficos de colunas do número de árvores $(A)$ e a área de cobertura por árvore (B) para os lados Nascentes e Poentes das ruas Paralelas. 
Figura 7. Gráficos de coluna da distância entre as árvores e da cobertura vegetal para os lados Poentes e Nascentes das ruas Paralelas

Figure 7. Charts column on the distance between the trees and vegetation to the sides of sunsets and springs parallel streets

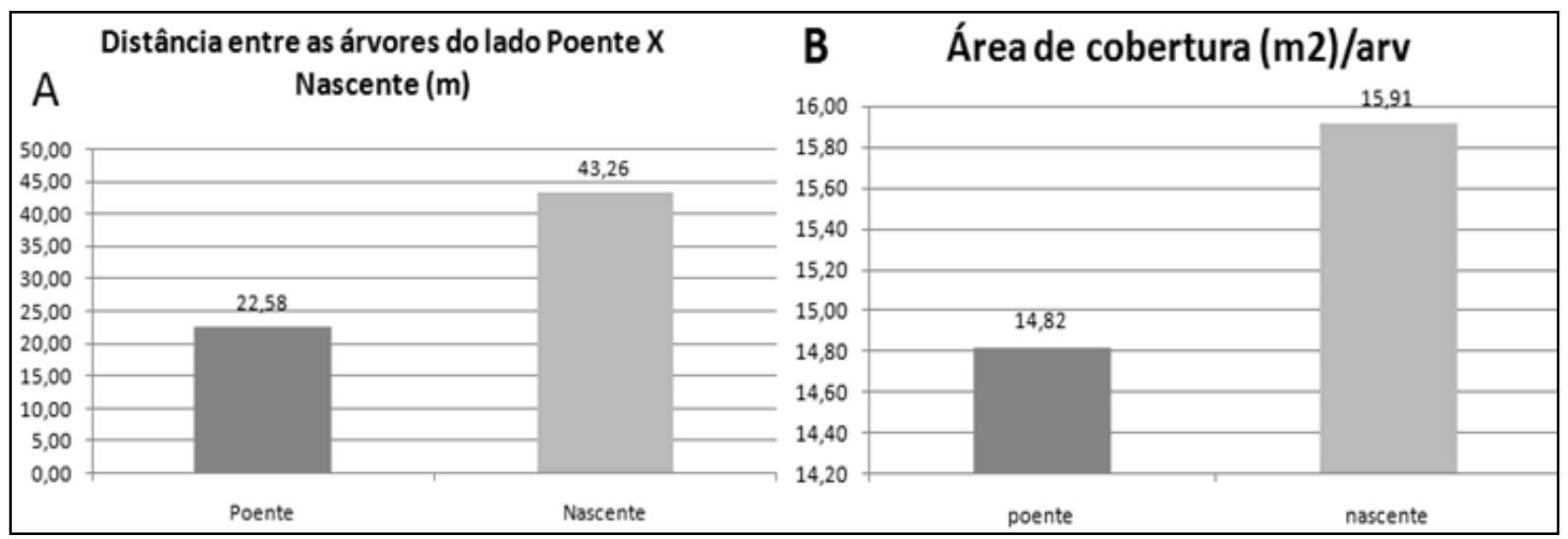

As ruas Paralelas recebem a radiação solar durante mais tempo ao longo do dia do que as ruas transversais, pois nas ruas Paralelas o sombreamento provocado pelas construções é menor do que nas ruas transversais. Dependendo do ângulo de inclinação, o sol da tarde ainda pode ser considerado um incômodo respeitável nas ruas Paralelas.

Camacho (2011) pesquisou entre outros assuntos a influência da altura das árvores no recebimento de luz solar pelas residências em Portugal, lá em Portugal, por ser um país de clima temperado, a preocupação é a inversa, ou seja, o planejamento é pensado para que os prédios recebam o máximo de luz solar possível, Boukhabi e Alkam (2012) pesquisando sobre o impacto das árvores nas condições térmicas em uma rua da cidade Biskra na Argélia citam que as árvores existentes nas calçadas servem de barreira para o sol direto, concluem que as árvores diminuem a temperatura ambiente, porém eles não dimensionam o número e o tamanho das árvores.

No gráfico $(A)$ nota-se que o adensamento das árvores nos lados Poente é maior que no Nascente, esse resultado é percebido intuitivamente por quem percorre as ruas de Serra Talhada com atenção para o tema, essa percepção se confirma estatisticamente ao nível de $5 \%$ pelo teste $F$, que fornece um $\mathrm{p}$-valor de 0,0028 . Esse resultado é esperado e confirma a existência de diferença significativa para a distância entre as árvores dos lados Poentes e Nascentes.

Quanto à área de cobertura não houve diferença significativa ao nível de 5\%, novamente aqui, não existiu diferenciação para o tamanho das copas, o teste $\mathrm{F}$ forneceu um p-valor de 0,7063 descartando assim a existência de diferenciação entre os lados Poente e Nascente das ruas Paralelas. 
Comparando o tamanho médio das copas por árvores com outros trabalhos, é visível a pequena área de cobertura que cada árvore fornece em Serra Talhada devido ao arraigado hábito da população de podar constantemente as árvores dando formas geométricas as copas como também não permitindo o crescimento em altura das árvores, a altura média das árvores em Serra Talhada é de 2,98 metros.

O hábito da poda e sua futilidade foram pesquisados por Fabião e Silva (1994) que afirmam que além de prejudicial às árvores pela facilitação de ataque de patógenos, perda de cobertura vegetal, prejuízo estético entre outros, existe o prejuízo financeiro, pois árvores mal podadas tendem a ter um aumento na produção de galhos o que tornará dentro de pouco tempo a gerar nova necessidade de poda.

A tabela 1 resume os resultados das comparações realizadas.

Tabela 1. Comparação entre as ruas e os lados. $\mathrm{DM}=$ distância média entre as árvores. $\mathrm{AC}$ = áreas média de cobertura por árvore. Sim = diferença significativa. Não = diferença não significativa

Table 1. Comparison between the streets and the sides. $\mathrm{DM}=$ average distance between trees. $A C=$ average coverage area per tree. Yes $=$ significant difference. No = nonsignificant difference

\begin{tabular}{|c|c|c|c|c|c|c|c|}
\hline Tipo & Comparação & $\mathrm{DM}(\mathrm{m})$ & p-valor & Decisão & $A C\left(m^{2} / a r v\right)$ & $\mathrm{p}$-valor & Decisão \\
\hline Rua como um todo & $\begin{array}{l}\text { Transversal } \\
\text { Paralela }\end{array}$ & $\begin{array}{l}26,74 \\
22,02\end{array}$ & 0,12 & Não & $\begin{array}{l}16,30 \\
15,29\end{array}$ & 0,22 & Não \\
\hline Lado Poente & $\begin{array}{l}\text { Transversal } \\
\text { Paralela }\end{array}$ & $\begin{array}{l}24,25 \\
22,55\end{array}$ & 0,60 & Não & $\begin{array}{l}15,83 \\
14,51\end{array}$ & 0,45 & Não \\
\hline Lado Nascente & $\begin{array}{l}\text { Transversal } \\
\text { Paralela }\end{array}$ & $\begin{array}{l}62,94 \\
42,65\end{array}$ & 0,07 & Não & $\begin{array}{l}12,67 \\
15,30\end{array}$ & 0,14 & Não \\
\hline Rua Transversal & $\begin{array}{l}\text { Poente } \\
\text { Nascente }\end{array}$ & $\begin{array}{l}24,47 \\
64,28\end{array}$ & 0,00 & Sim & $\begin{array}{l}14,97 \\
16,31\end{array}$ & 0,03 & Sim \\
\hline Rua Paralela & $\begin{array}{l}\text { Poente } \\
\text { Nascente }\end{array}$ & $\begin{array}{l}22,58 \\
43,26\end{array}$ & 0,00 & Sim & $\begin{array}{l}14,82 \\
15,91\end{array}$ & 0,70 & Não \\
\hline
\end{tabular}




\section{CONCLUSÕES}

O sol Poente incidindo diretamente na frente da casa (lado Poente da rua Transversal) faz com que mais moradores das plantem árvores. Quando o sol Poente não incide tão diretamente na frente das casas (lado Poente das ruas Paralelas) mais moradores plantam árvores na frente da casa, porém essas árvores não possuem copas maiores do que as árvores em outras condições de localização.

A maioria das árvores da cidade possuem copas com tamanho quase padronizado, excetuando as localizadas nas calçadas Nascentes das ruas transversais que são maiores do que as árvores do lado Poente das ruas transversais.

\section{REFERÊNCIAS}

ALVAREZ, I. A. Qualidade do espaço verde urbano: Uma proposta de índice de avaliação. Tese (doutorado em agronomia) - Escola Superior de Agricultura Luiz Queiroz, Universidade de São Paulo, São Paulo. 2004.

BOUKHABL, M. e ALKAM, D. Impact of vegetation on thermal conditions outside, thermal modeling of urban microclimate, case study: the street of the Republic. Rev. Energy Procedia. Biskra. v. 18, p 73-84. 2012.

CALIXTO JÚNIOR, J. T.; SANTANA, G.M.; DRUMOND, M. A.; OLIVEIRA, V. R. de. Análise da cobertura vegetal por inventário censo na zona urbana de um município do interior cearense. II Congresso Nordestino de Engenharia Florestal. Campina Grande - PB. nov/ 2009.

CAMACHO, G. B. A energia solar e a utilização racional de energia em edifícios de acordo com os regulamentos em vigor. Dissertação (Mestrado em Tecnologia da Madeira). Universidade da Madeira. Centro de Ciências e Tecnologia da Madeira. Portugal. 2011.

FABIÃO, A.; SILVA, H. J. As "podas camarárias": considerações sobre a futilidade de um acto de mutilação. Revista Florestal. v. 7, p. 37-45, 1994.

FROTA, A. B. e SHIFFER, S. R. Manual de conforto térmico. São Paulo: Ed. AMBUP Comercial Itda. $7^{a}$ edição. 242 p. 2006.

IBGE - Instituto Brasileiro de Geografia e Estatística. Censo Demográfico de 2010. Disponível em: <http://www.ibge.gov.br/cidadesat/topwindow.htm?1>. Acesso: 08/11/2012. 
KLÜPPEL, G. P. Traçado e clima urbano em Salvador no século XIX. In: Seminário da História da Cidade e Urbanismo. Salvado - BA. 2000. v. 6, n. 2. Disponível em: <http://www.anpur.org.br/revista/rbeur/index.php/shcu/article/view/778/753>. Acesso em: 08/11/2012.

LUNDGREN, W. J. C.; SILVA, L. F. da; ALMEIDA, A. Q. de. Influência das espécies exóticas arbóreas urbanas na área de cobertura da cidade de Serra Talhada - PE. REVSBAU, Piracicaba - SP, v.8, n.3, p 96-107, 2013.

MASCARÓ, J. J.; PEDROTTI, A.; VIEIRA, M. A vegetação como instrumento de apoio à sustentabilidade dos espaços urbanos e edificações. I Encuentro Latino Americano de Universidades Sustentáveis: Universidades Sustentáveis, Possibilidades e Desafios. Disponível em: <ftp://ip20017719.eng.ufjf.br/public/Sustentabilidade/ELAUS2008/trabalhos 1525.pdf>. Acesso em: 18/11/2012.

MASCARO, J. J. Significado ambiental-energético da arborização urbana. Revista de Urbanismo e Arquitetura. v. 7, n. 01, p. 32 - 37. 2006. Disponível em: <http://www. portalseer.ufba.br/index.php/rua/article/view/3151/2263>. Acesso em: 06/12/2012.

MILANO, M.S.; DALCIN, E. Arborização de vias públicas. Rio de Janeiro: Ligth, 226 p. 2000.

NASCIMENTO, L. R. do et al. Percepção dos moradores de Serra Talhada - PE sobre arborização urbana. IX Jornada de Ensino, Pesquisa e Extensão - JEPEX. UFRPE. 2009.

ROCHA, R.; PIMENTEL, R. M.; BARRETO, R. C. Censo da Arborização Viária de um Bairro da Cidade do Recife, Pernambuco, com a Utilização de um Sistema de Informação Geográfica. Revista Brasileira de Geografia Física, v. 5, n. 2, p. 285-301, 2012.

SAMPAIO, A. C. F. e DE ANGELIS, B. L. D. Inventário e análise da arborização de vias públicas de Maringá-PR. Revista da Sociedade Brasileira de Arborização Urbana, v 2, n 2, p. 37-57, 2007.

SIMPSON, J. R. Improved estimates of tree-shade effects on residential energy use. Energy and Buildings. v 34. Issue 10. p. 1067-1076, 2002.

TROY, A.; GROVE, J. M.; O'NEIL-DUNNE, J. The relationship between tree canopy and crime rates across an urban-rural gradient in the greater Baltimore region. Landscape and Urban Planning, v 106, p. 262-270, 2012. 